\title{
THE CLASSROOM DOOR
}

\author{
YAO SHEN \\ University of Michigan
}

The classroom door is an important line of demarkation in the profession of a modern language teacher. His duties vary in relation to the specific side of the door. That is, what he does as a teacher before and after he enters the door can be extremely different. It is not the purpose of this article to exhaust the imperatives required of a modern language teacher. Rather it is to raise a few fundamental questions for the self-examination of such teachers.

There are two questions the modern language teacher must without choice ask himself before he enters the classroom. The first one is, "Have I done a comparative linguistic analysis between the students' native language and the foreign language they are going to learn?" If the answer is "No," it is obvious that he has not given himself up-to-date preparation. If his answer is "Yes," he must go on and ask himself a consequential question: "Is my comparative analysis an item-for-item one or is it a related one?" An item-foritem comparison is certainly better than no comparison. But it is not as satisfactory as a related one. Examples are given below to show the difference.

In the matter of the comparison of sounds to be found in English and in Mandarin Chinese, one will notice that in both languages there is the sound [f]. But to know that the sound $[\mathrm{f}]$ is found in both languages is not enough. Further analysis will show that in English, [f] can occur in utterance initial and utterance final as in fine and knife. In Chinese, [f] occurs in utterance initial as in "fân"(cooked rice) but not in utterance final. Besides, in English, there are also the following initial consonant clusters with [f]:

$$
\begin{array}{llll}
\text { fr- } & \text { freedom } & \text { fl- } & \text { flee } \\
\text { fy- } & \text { fuel } & \text { sf- } & \text { sphere }
\end{array}
$$

and the following final consonant clusters: ${ }^{1}$

\footnotetext{
${ }^{1}$ See Charles C. Fries, Teaching and Learning English as a Foreign Language, (Ann Arbor, 1946) pp. 17-19.
} 


\section{LANGUAGE LEARNING}

$\begin{array}{llll}{[-f t]} & \text { soft } & {[- \text { lf }]} & \text { self } \\ \text { [-fs ] } & \text { laughs } & {[-\mathrm{mf}]} & \text { mymph } \\ {[-\mathrm{f} \theta]} & \text { fifth } & {[-\mathrm{lfs}]} & \text { golfs } \\ {[-\mathrm{fts}]} & \text { lifts } & {[-\mathrm{mfs}]} & \text { nymphs } \\ {[-\mathrm{f} \theta \mathrm{s}]} & \text { fifths } & {[-\mathrm{lft}]} & \text { engulfed }\end{array}$

None of the above consonant clusters, either initially or finally, can be found in Mandarin Chinese. Thus, to say that English and Mandarin Chinese both have [f] and therefore it can be assumed that there would be no trouble in teaching [f] to Chinese speakers is only an item-for-item comparison. One must see how [f] patterns with other sounds both in English and in Mandarin Chinese.

This related comparison is also importani with regard to morphology and syntax. To know that English uses inflection, function words, and word order to indicate "structural" 2 relations and Mandarin Chinese uses function words and word order is fine, but not enough. English teachers of the last generation who taught the students to memorize "bring, brought, brought; buy, bought, bought; teach, taught, taught" were only teaching inflection as units instead of the relationship of each one of these words in sentence patterns. For example: "I bring books to class everyday" and "I brought books to class (everyday) last week." 3 For the teacher who teaches English as a foreign language to Mandarin Chinese speakers, for example, it is additionally necessary for him to compare the "structural" devices used in sentence patterns in both languages. Four examples are given below:

$\begin{array}{lllll}\text { Example } 1 & \text { English: } & \text { You study } & \text { He studies } \\ & \text { Chinese: } & \text { ni } & \text { niàn ta niàn }\end{array}$

A unit-for-unit comparison between the first set of sentences will show that English and Chinese can be interpreted as having neither inflectional difference nor word order difference in "You study" and "nǐ nian."

\footnotetext{
2 See Charles C. Fries, The Structure of English, (New York, 1952).

${ }^{3}$ See Patterns of English 'Sentences, English Language Institute, University of Michigan, 1953, and An Intensive Course in English for Chinese Students, by Charles Fries and Yao Shen, English Language Institute, University of Michigan, 1946.
} 


\section{THE CLASSROOM DOOR}

Example 2

English: Do you study
Chinese:

In English, the question function word do comes at the beginning of the sentence; in Chinese, the question function word ma comes at the end of the sentence. The word order is different, although the use of a function word to indicate a question is the same.

Example 3

English: You studied

Chinese: nY nian le

In English, tense is indicated by inflection; in Chinese, tense or a spect is indicated by function word and word order. The function word here is le, and le comes after nidn.

Example 4

English: Did you study
Chinese:

In English, the word did has three syntactical functions. First, it indicates tense; it is not do or does. Second, it serves as the function word added to a statement to make the sentence a question. Third, it has word order importance. That is, did comes at the beginning of the utterance. In Chinese, tense or aspect is indicated by the function word le; the question is signalled by the function word $m a$. The word order is: le comes after niàn, and ma comes after le. The above four examples have shown that the morphology and syntax of a language are not made up of a list of units but a list of related units.

\begin{tabular}{|c|c|c|c|c|c|}
\hline & English & \multicolumn{4}{|c|}{ Chinese } \\
\hline $\begin{array}{l}\text { Do } \\
\text { Did }\end{array}$ & $\begin{array}{l}\text { You study } \\
\text { you study } \\
\text { You studied } \\
\text { you study }\end{array}$ & $\begin{array}{l}\text { nı̌ } \\
\text { nY̌ } \\
\text { nY̆ } \\
\text { nı̆ }\end{array}$ & $\begin{array}{l}\text { niàn } \\
\text { niàn } \\
\text { niân } \\
\text { niàn }\end{array}$ & $\begin{array}{l}\text { le } \\
\text { le }\end{array}$ & $\begin{array}{l}\mathrm{ma} \\
\mathrm{ma}\end{array}$ \\
\hline
\end{tabular}

In the teaching of a foreign language, one system of related units must be compared with another system of related units.

The subject of vocabulary must be treated in the same way. Charles C. Fries' emphasis on no word-for-word translation is of serious linguistic significance. The Spanish parting 
greeting "adiós" can be translated into English as "Goodbye." But a Spanish speaker learning to speak English will greet the friend he meets at night with "Good night." This is perfectly logical. If he meets his friend in the morning, the greeting words are "Good morning"; in the afternoon, "Good afternoon"; in the evening, "Good evening"; therefore at night, "Good night." He does not realize that "Good night" is an alternant for "Goodbye" in the evening or at night. It is not enough to be aware of the danger of word-for-wordtranslation, one must also understand expressions as elements in the total cultural pattern of the people. Two people meet each other while walking. The English-speaking person says, "Good morning," "Good afternoon," "Good evening," "How are you?" "Hello," or "Hi." The Spanish-speaking person says, "Goodbye." The former is thinking of the meeting aspect of the situation; the latter is thinking of the parting aspect of the situation. And in the latter's native language he says, "adiós." Consequently in his foreign language he says, "Goodbye." In other words, the way people are brought up to look upon the same situation can be different or patterns of culture can be different. And the linguistic expressions used thus can be different too.

From the above illustrations, we see that the foreign language teacher not only analyses the two languages concerned, he also compares them. In his comparison, he not only makes a unit-for-unit comparison, he also looks upon the language as a system of related items in sounds, in morphology and syntax, and in vocabulary. Not only is he aware of linguistically related units, he is also keenly sensitive to the fact that language and culture are tied together

The role of the modern language teacher once inside the classroom door is entirely different. His duty is primarilyin fact, fundamentally - the application of such techniques in which the results of linguistic research are used. Such results come from the work he has done before he enters the classroom. His aim is to help the students to attain oral control of the language with the least waste of time and effort and the maximum amount of achievement. There are some essential points that he must always keep in mind. The most important question is, "Who is learning to speak the 


\section{THE CLASSROOM DOOR}

language?" And the answer had better'be "The students." If so, the next question he should ask himself is, "Am I giving the students the maximum opportunity to practice, since no one can learn to speak a language without production."

The goal of giving the students the maximum opportunity to practice can be reached by a combination of affirmative and negative approaches. First, explanations should be short and clear and without waste of words. Many useful examples must be given so that students can repeat with the teacher and by themselves. Second, inside the classroom is not the place for the teacher to exhibit his knowledge about linguistics. It is essential for him to remember that any amount of time he spends talking about linguistics, the aim of which is not toward the practice of the language by the students, is a mark against his professional skill. He is taking away from the students time needed for gaining oral control. A cardinal sin! Third, a modern language class is primarily not a class about the language but a place where the students have the opportunity to produce the language. There are classes which are conducted in the following way with the following result:

Teachers: The vowel sound [i] in English is high, front, unrounded, and open.

The vowel sound [I] in English is high, front, unrounded, and closed.

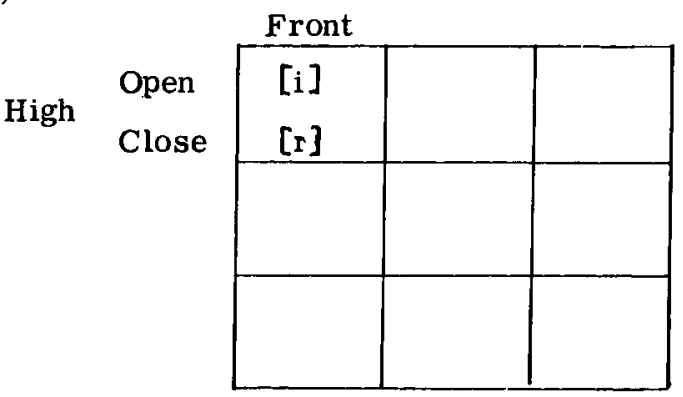

What kind of a vowel sound is the English [i] ?

Students: High, front, unrounded, and open.

Teacher: What kind of a vowel sound is the English [1] ? 
Students: High, front, unrounded, and closed.

Then the teacher repeats some of the examples with the students in which the sole difference is [i] and [I], i.e., feel, fill; meal, mill. The next day, the students are asked what kind of vowel sounds [i] and [r] are. The students give the appropriate description of each sound. All is very well, except the class should spend more time on the production of the sounds and less on the description of them. Knowing the description of the sounds does not always result in a satisfactory production of the sounds. Students that have gone through such classes often show very low scores in aural comprehension and invariably show lower scores in oral production.

A constructive remedy for such a situation is decreased emphasis on exposition and discussion of the nature of the sounds and increased emphasis on exercises toward production; i.e., repetition with students in unison, repetition with students individually, hearing exercises in which students are to identify the sounds to be distinguished, and production exercises in which they are requested to produce such sounds. 4 Thus time spent about the language is reduced to a minimum and time spent on the production of the language is increased to a maximum.

A related fact concerning this matter of about the language is the avoidance of waste of time discussing linguistic features. Often time is spent on the description of linguistic features in the students' native language. Such a discussion should be reduced as much as possible. First, students are here to learn to speak the foreign language. They are not here to get the linguistic analysis of their native language. Second, technical linguistic description is often above the linguistic receptive ability of the class, and therefore the teacher leaves a certain number of the students uninterested, often bewildered, and not particularly impressed. Third, often the students can mistake the description of their native language

\footnotetext{
${ }^{4}$ See English Pronunciation, English Language Institute, University of Michigan, 1954.
} 


\section{THE CLASSROOM DOOR}

as a criticism of it. Even if the students should admit that the teacher's description is correct, there is always a time when some student can "dig up an exception" to the teacher's general description and a fruitless discussion begins. Fourth, the teacher may succeed in impressing the students with how much he knows about their native language, but he has then failed to help them acquire more productive skill in the foreign language. All these can be avoided if the teacher concentrates on the students' production of the language.

The purpose of this article is not to exhaust the techniques of linguistic analysis and language teaching, both of which are required of the modern language teacher. It is only to emphasize the classroom door as a line of demarkation or a signal to remind the modern language teacher that his duties before and after he enters the room are different and that the two aspects of his responsibility must not be confused. 